\title{
Study on the Translation Teaching based on the Cultural Differences between Chinese and English
}

\author{
H.M. ZHAO \\ Teaching and Research Institute of Foreign Languages, Bohai university, Jinzhou 121013, China
}

\begin{abstract}
Cultural differences determine that there are huge differences in the thinking logic, sentence structure and expression habits between Chinese and English. These become the big obstacles in translation between Chinese and English. In this article, the author discusses the language differences from the perspectives of language habits, customs, thinking mode and religions, analyzes the excellent examples of translation and proposes the strategies on the translation teaching of college English.
\end{abstract}

KEYWORD: Cultural differences; Translation; Thinking mode

\section{INTRODUCTION}

With the proceeding of globalization, nations all over the world exchange their cultures more frequently. $\mathrm{Hu}$ Wenzhong, a Chinese linguist, defines the culture as follows. "Culture is the product that people have created through long time efforts, and it is the social heritage. The core of culture is the concept of value, and it can distinguish difference cultures according to their different value concepts." People from different cultures want to know the cultures of other nations through books, audio and video products. Therefore, it is necessary to convert these cultural works from one language to another language. So the translation emerges. Knight, an American translation theorist, believes that the translation refers to the equivalence that is the most appropriate and natural reproduction of the original language from language to style in the receptor language. Therefore, the essence of translation is to find the equivalence that is most appropriate to the other language[1]. Due to the cultural differences, translation between languages is often a very difficult thing. Language is the carrier of culture and also the precipitation of history. A well known thing in one culture may be unacquainted for the people in other cultures. In order to achieve the equivalence translation, the translators must be required to have sufficient understanding on the target language culture and can find the equivalence of language between two cultures. Therefore, the translator must have sufficient knowledge and well knows the concept, customs, beliefs and moral values of target language culture. The translator must be faithful to express the meaning of the original works and at the same time does attract the interest of foreign crowd. In the following parts, the author will analyze the cultural difference between Chinese and English language and puts forward to the strategies on translation teaching.

\section{CULTURAL DIFFERENCES BETWEEN CHINESE AND ENGLISH}

(1) Differences of linguistic habits. English and Chinese belong to two different language families. English belongs to the Indo-European language family while Chinese belongs to Sino-Tibetan language family. English differs from Chinese in many expression habits. English tends to express movement by using fewer verbs while Chinese often uses verbs. The pivotal sentences and the sentences with serial verb phrases are often used in the expressions of Chinese. For example, "The doctor's extremely quick arrival and uncommonly careful examination of the patient brought about his very speedy recovery", from this sentence we can learn that the nominalization of verb is often used in English to express the meaning of actions, such as the words 'arrival' and 'examination'. This makes the expression more concise and natural than the expression with using of verbs. If this sentence is translated into Chinese, a series of verbs are used in the expression. Due to the lack of variable forms of English verbs, if needed, the only way to express the meaning of movement is to use the verbs frequently. In the active and passive aspects, English tends to 
use the passive voice. This is because the subjects of English expression are often the abstract or inanimate objects. Chinese prefers the subjective thinking and often subjectively describes the objective things. Therefore, the active voice is more inclined to use in Chinese. For example, "New actions must be taken to prevent air pollution", if translated into Chinese, the active voice must be used, otherwise, it is very awkward. Moreover, English prefers the abstract expression while Chinese prefers the concrete expression. Abstract nouns are often used in English expression while concrete verbs are used in Chinese expression. For example, "The absence of intelligence is an indication of satisfactory developments". In this sentence, the words of 'absence', 'intelligence', and 'indication' are abstract nouns. If it is translated into Chinese, the abstract nouns must be converted into concrete nouns[2].

(2) Difference of habits and customs. In translation, people should pay attention to not only the accuracy of words, but also the connotations of words. However, the connotations of words are determined by the according culture. So if the translator is not familiar with the culture of target language, he will make the errors of understanding or pragmatic failure in translation. For instance, one can occasionally see a red or black car sprayed with "I am yellow" in the streets of America. If it is translated into Chinese by word-for-word translation, Chinese people will be puzzled with it. In China, a yellow person means that he is vulgar and obscene. In fact, the taxi is usually yellow in American culture. So yellow usually means a taxi. Therefore, the correct translation should be 'this is a taxi'. Moreover, in the American culture, many idioms are involved with dog. American usually regard dog as the faithful friend of human being. Therefore, the idioms with dogs are usually positive, such as 'a lucky dog', 'love me, love my dog' and 'give a god a bad name and hang him' and so on. However, in China, the meaning of dog is usually derogatory and insulting. People usually call their disgusted people dog. In China, people usually call a henpecked man tracheitis because the two words are homonyms. If the joke is translated into "He suffers from tracheitis", the foreigners will be puzzled and never feel funny. The foreigners will ask with puzzles: So what? Why are you laughing so hard when he is suffering from tracheitis? This is obviously a pragmatic failure of translation. Although it can basically express the meaning by translating into "He is an obedient husband", the original humor loses. If it is translated into " $\mathrm{He}$ is a henpecked man", the translation will be more vivid[3].

(3) Differences of thinking mode. The thinking mode is the way in which people think about and understand the outside things. It is formed in the long history of human evolvement. Due to the different environment of China and Europe, people in these regions have different customs, habits and living conditions. Therefore, these factors facilitate the unique mode of thinking for the language. Generally, westerners prefer the abstract thinking. This philosophical thinking is initiated by Aristotle since the time of ancient Greek. In contrast, Chinese is deeply influenced by Confucianism and tend to seek and confirm the outside world from the inner feelings in the process of cognition. Therefore, the understanding of external world is full of sensibility and concretization for Chinese. In the expression, English is full of rigorous logic and the sequence of logic is from primary to secondary. Usually, the main information is presented first in the sentence of English and other auxiliary information, such as time, place etc. is introduced subsequently. In contrast, Chinese prefer the scatter thinking and the expression is arrayed by various relation, such as the sequence of time, causality and so on. Similarly, English prefers the formal logic, that is, hypotaxis. In the expression, various conjunctions are used to express their connection. Contrary to this, the syntactic structure of Chinese prefers parataxis. In the expression, the components of sentence are mainly connected by the semantic background or context, but the conjunctions are seldom used. For example, "If I had known it would come to this, I would have acted differently." In this sentence, the conjunction is used to denote the relation of conditions and results, which accords with the characteristics of hypotaxis. If it is translated into the saying of Chinese, the sentence consists of two clauses while no conjunction is used. However, from the perspective of logic, the two clauses have the subordinate relationship and the expression is much succinct. For example, "As we lived near the road, we often had the traveler of stranger visit us to taste our gooseberry wine, for which we had great reputation, and I confess, with the veracity of an historian that I never knew one of them to find fault with it." This complex English sentence is composed of complex sentences, attributive and adverbial clauses. In this sentence, there are many substituting and relational words, which looks like 'the entangled vine'. But one can find that the sentence trunk is clear and the logic is very strict although there are many modified language components. If it is translated into Chinese, a series of clauses are used and each clause must contain one verb at least[4].

(4) Differences of religion and history. In western culture, Christian occupies an important position. Therefore, westerners believe in God. In Contrast, most Chinese believe in Buddhism. In China, many allusions are involved with Buddhism, such as the well known story of three monks carrying water. If 
the allusion is translated literally, it will be puzzling to the westerners. They do not know why three monks have no water to drink because the westerners are unfamiliar to the Buddhism and monks. Therefore, it can be translated into "One boy is a boy, two boys half a boy, three boys no boy", which is familiar to the westerners. For example, "Being a teacher is being present at the creation, when the clay beings begin to breathe." If the sentence is translated literally into Chinese, it will puzzle the Chinese. They do not understand why the clay can breathe. However, if the people know about the Christian, he can remember the story in the Holy Bible that God created man using mud. Thus this sentence means that people begin to receive education from teacher at a very early age. For example, the Chinese idiom "debacle" is much difficult to be translated into English. If one uses the English allusion skillfully, it will be translated into "meet one's Waterloo". People familiar with the western history will know that Napoleon once was defeated completely in the battle of Waterloo which led to the final downfall of his empire. So the translation with this story can express the meaning of Chinese idiom vividly. For example, in the memorial hall of Jigong, Lanxi, Zhejiang province, the introduction is translated as "Jigong, Robin Hood in China, robbed the rich and helped the poor". In the translation, the translator likens Jigong to Robin Hood, which is a familiar role to the westerners. The translator does not painfully explain the role of Jigong to the westerners and the westerners will have a deep impression on Jigong. Therefore, this translation makes Jigong intimate and familiar to the westerners.

\section{STRATEGIES ON THE TRANSLATION TEACHING OF COLLEGE ENGLISH}

Chinese students have been long influenced by the native culture. They have formed the inherent psychology and thinking modes. This thinking mode has significantly affected the learning of English. It is the key of college English translation that the teacher eliminates the negative impact brought by the Chinese thinking mode and stimulates the students' interest of western culture. The author puts forward several strategies as follows.

(1) Teacher should increase the knowledge of English culture for the students. Due to the influence of traditional teaching mode and the examinationoriented education, Chinese students rarely read the books about western culture. Thus there is too little knowledge input of English culture. Although some cultural courses are established in a few universities, they are intended to improve the English language ability, but not the ability of cross-cultural communication. If there is not a large amount of cultural information input, the translation education will be nothing. Therefore, for the teaching of English translation, the teacher should not only teach the students the vocabulary, but also the knowledge of western economic system, politics, education, culture, history, religion and folk customs. The teacher should help the students acquire the knowledge of English culture. In order to improve the ability of English translation, students should actively learn the cultural knowledge by reading more western culture books. Teachers should refer to the students a series of excellent English novels and movies about history. These materials can make the students acquire the history knowledge of Europe and America. At the same time, teacher should ask the students to summarize the English novels and give a simple summary. To stimulate the interest of western culture, the teacher should recommend some films to the students, such as the BBC documentary series of archaeology film and the films of American westward movement[5].

(2) Teacher should perform the contrastive analysis on the western culture. Teacher is much important for the students to acquire the cultural information. Also teacher is the key factor that can help the students to overcome the difference of culture. A good teaching method can stimulate the cultural interest of students and enhance their learning initiatives. Teacher should perform the contrastive analysis on the western culture and impress the students with those exotic customs and history. The teacher should create the cultural atmosphere by using the multimedia and network. Teacher uses the Internet to show the news, films and videos to the students and analyzes the behaviors and customs of westerner. This can expand the cultural knowledge of students and stimulate their learning interest.

\section{CONCLUSION}

Cultural difference determines that there are large differences in the religious belief, ethics, values and thinking mode between Chinese and European. As the carrier of culture, language is greatly affected by the culture difference and therefore great differences lie in the thinking mode, semantic structure and expression habits. These have become the big obstacle in the translation between English and Chinese. As the translator, one must be proficient in English and Chinese culture and history and finds the equivalence between two languages. Therefore, teacher should take the contrastive analysis method in the English translation teaching. At the same time, the teacher should input more cultural information to the students and stimulate their interest of culture. 


\section{ACKNOWLEDGMENTS}

This work is part of the project of Research on Taskbased English Teaching Mode Based on Constructivism Theory. The work has been supported from the fund of Liaoning Provincial Federation Social Science Circles (No. 2015 lslktziwx-03), and also from the fund of Liaoning Planning Office of Philosophy and Social Sciences (L13CYY018).

\section{REFERENCES}

[1] Gudykunst W. B., 2003, Cross-Cultural and Intercultural communication, Sage Publications, Inc.

[2] Hatim, B. 2001, Communication Across Cultures: Translation Theory and Contrastive Text Linguistics, Shanghai: Shanghai Foreign Language Education Press.

[3] Lefevere, A.1992, Translation/History/Culture: A Sourcebook. London and New York: Routledge.

[4] Luo Xuanmin, 2011, New English-Chinese Translation Course, Tsinghua University Press. (in Chinese)

[5] Valdes, J.M., 1986, Culture Bound: Bridging the Cultural Gap in Language Teaching, Cambridge University Press. 